\section{Mucin-like cancer associated antigen}

S. Holdenrieder ${ }^{1}$ und P. Stieber ${ }^{2}$

${ }^{1}$ Institut für Laboratoriumsmedizin, Deutsches Herzzentrum München, Klinik an der Technischen Universität München, München, Deutschland

${ }^{2}$ Institut für Laboratoriumsmedizin, Klinikum der Universität München (LMU), München, Deutschland

\section{$\operatorname{Synonym(e)~MCA~}$}

Englischer Begriff mucin-like cancer associated antigen

Definition MCA ist ein 350-500 kDa schweres muzinöses Glykoprotein.

Struktur MCA ist ein hoch molekulares Kohlenhydratantigen mit einer hohen Zahl geladener Gruppen wie $\mathrm{N}$-Acetylsialinsäure, Fukose, Galaktose und Galaktosamin, die über Threonin und Serin an eine Proteinstruktur gebunden sind. Das muzinähnliche Antigen liegt auf der Polypeptidkette repetitiv vor und wird durch den monoklonalen Antikörper b-12 erkannt.

Molmasse $350-500 \mathrm{kDa}$.

Synthese - Verteilung - Abbau - Elimination Immuhistologisch detektiert der b-12-Antikörper normales Gewebe der Brustdrüse und der Niere; außerdem werden Mammakarzinome und Adenokarzinome anderer Genese dadurch erkannt.

\section{Halbwertszeit $2-5$ Tage.}

Funktion - Pathophysiologie MCA kann wie alle Muzinmarker zu Therapiekontrolle und Nachsorge des Mammakarzinoms eingesetzt werden. Wegen nicht vorhandener Kom- plementarität $\mathrm{zu}>$ Carbohydrate antigen 15-3 und MCA ist eine Kombination nicht sinnvoll. Als Zweitmarker empfiehlt sich CEA ( $\triangleright$ Carcinoembryonales Antigen).

Untersuchungsmaterial - Entnahmebedingungen Serum, Liquor, Pleura-, Aszitesflüssigkeit.

Analytik $>$ Enzymimmunoassay (EIA), $>$ Radioimmunoassay (RIA), - Immunradiometrischer Assay (IRMA).

Konventionelle Einheit U/mL (kU/L).

Referenzbereich - Erwachsene Empfohlener Referenzbereich im Serum bis $15 \mathrm{kU} / \mathrm{L}$ (methodenabhängig).

Indikation Therapiekontrolle und Nachsorge beim Mammakarzinom (mit CEA).

Interpretation Neben dem Mammakarzinom kann MCA auch bei Karzinomen des Kolons, des Pankreas, der Gallengänge, der Leber, der Lunge, des Ovars, des Endometriums, der Zervix, der Niere sowie der Prostata erhöht sein.

Hinsichtlich benigner Erkrankungen sind gutartige Lebererkrankungen und benigne Erkrankungen der Brust als Einflussgrößen zu nennen.

Diagnostische Wertigkeit Mammakarzinom: Therapiemonitoring, Rezidiverkennung (mit CEA).

\section{Literatur}

Lamerz R (2007) MCA. In: Thomas L (Hrsg) Labor und Diagnose. Indikation und Bewertung von Laborbefunden für die medizinische Diagnostik, 7. Aufl. TH-Books, Frankfurt am Main, S 1313-1316

Stieber P, Heinemann V (2008) Sinnvoller Einsatz von Tumormarkern. J Lab Med 32:339-360 